\title{
PERENCANAAN JETTY TERSUS STORAGE TANK NATPAC LAMONGAN
}

\author{
Arifien Nursandah ${ }^{1)}$, Topan Wijaya ${ }^{2)}$ \\ ${ }^{1)}$ Prodi Teknik Sipil, Fakultas Teknik, Universitas Muhammadiyah Surabaya \\ JL. Sutorejo No. 59 Kota Surabaya, Jawa Timur, 61135 \\ E-mail: arifien.nursandahums@gmail.com \\ ${ }^{2)}$ Prodi Teknik Sipil, Fakultas Teknik, Universitas Muhammadiyah Surabaya \\ JL. Sutorejo No. 59 Kota Surabaya, Jawa Timur, 61135 \\ E-mail: topanwijaya1992@gmail.com
}

\begin{abstract}
To anticipate the tendency of the oil crisis in Indonesia, PT. NATPAC GRAHA ARTHAMAS makes a special port for petroleum. So that facilities are needed to support the plan, special port for fuiling ship. The purpose of thesis is to plan a jetty structure that able to hold a maximum load of 50,000 DWT starting from collecting secondary oceanographic data, such as land data, structural modeling and jetty structure calculations, named breasting dholphin and mooring dholpin. The structure modeling using the Sap2000v14 program assistance from the results of analysis and modeling calculations, sap2000v14 get a breasting dholpin and mooring dholphin structure that safe against the jetty's effect. The foundation of precast concrete poles are using PP products with $\mathrm{D}=1 \mathrm{~m}$ is capable of receiving axial loads of up to 674.56 tons and $14 \mathrm{~m}$ deep. The breasting dholpin and dholpin mooring breasts are planned with the top evaluation of HWS $2.2 \mathrm{~m}$. For fenders are using OD x ID (1200 x 700mm).
\end{abstract}

Keywords: structure, fuiling ship port, pier

\begin{abstract}
Abstrak
Untuk mengantisipasi kecenderungan terjadinya krisis minyak di Indonesia, maka PT. NATPAC GRAHA ARTHAMAS membuat pelabuhan kusus untuk minyak bumi. Sehingga diperlukan fasilitas untuk mendukung rencana tersebut, yaitu dengan membangun dermaga minyak khusus. Tugas akhir ini bertujuan untuk merencanakan struktur jetty yang mampu menahan beban kapal maksimal 50.000 DWT dimulai dari pengumpulan data skunder hidro oseanografi , data tanah spt, pemodelan struktur dan perhitungan struktur jetty yaitu breasting dholphin dan mooring dholpin. Pemodelan struktur menggunakan bantuan program sap2000v14 . dari hasil perhitungan analisis dan pemodelan sap2000v14 diperoleh struktur breasting dholpin dan mooring dholphin yang aman terhadap gaya - gaya yang bekerja pada jetty. Pondasi tiang pancang beton precast menggunakan produk PP dengan $\mathrm{D}=1 \mathrm{~m}$ yang mampu menerima beban axial hingga 674,56 ton dan dipancang sedalam 14m.Breasting dholpin dan mooring dholpin direncanakan dengan elevasi puncak HWS 2,2m. Untuk fender menggunakan OD x ID (1200 x 700mm).
\end{abstract}

Kata kunci:struktur,terminal kapal tanker,dermaga

\section{PENDAHULUAN}

Penyimpanan dan transportasi saat ini merupakan faktor yang sangat penting dalam pengelolaan dan manajemen minyak bumi. Dengan pengelolaan yang efektif sebuah perusahaan dapat menerima keutungan yang sangat besar, dan sebaliknya jika pengelolaan ini amburadul maka akan memberikan kerugian yang besar terutama dalam hal biaya produksi.

Oleh karena itu diadakannya proyek pembangunan fuel tank di daerah Sedayulawas, Lamongan. Dalam proyek ini akan dibangun fuel tank yang nantinya akan digunakan untuk menampung minyak yang diangkut oleh kapal tanker. Dikarenakan kapal tanker yang membawa minyak memiliki DWT yang sangat besar hingga mencapai 50.000 DWT maka tidak dimungkinkan untuk kapal tanker mendekat ke pantai untuk mentrasnferkan minyak bumi. Oleh karena itu dibangunlah sebuah struktur jetty hingga mencapai kedalaman yang sesuai untuk kapal dengan DWT
50.000 untuk dapat berlabuh. Struktur jetty ini yang nantinya akan menjadi tempat bersandar kapal tanker tersebut. Struktur jetty tersebut nantinya akan disambungkan dengan trestel dan coasway yang akan menghubungkan jetty dengan daratan.

Dalam struktur jetty terdapat bangunan struktur breasting dolphin dan mooring dolphin. Breasting dolphin berfungsi sebagai tempat bersandar kapal sedangkan mooring dolphin berfungsi untuk menambatkan kapal agar kapal tidak mengalami banyak gerakan saat kapal berhenti. struktur ini sangat dibutuhkan karena saat kapal tanker mentrasnferkan muatannya menuju fuel tank maka kapal tidak diperbolehkan untuk melakukan banyak gerakan. Karena kondisi laut yang tidak menentu dikarenakan perubahan angin, gelombang dan arus, maka dalam mendesain jetty ini perlu memperkirakan gelombang, arus, Kita dapat menghitung elevasi jetty yang sesui pada tugas ahir ini juga akan dianalisa struktur jetty masih aman atau tidak. 


\section{METODELOGIPENELITIAN}

Tahapan yang dilaksanakan pada perencanaan adalah data-data yang dipakai :

Layout studi dilihat gambar dibawah ini

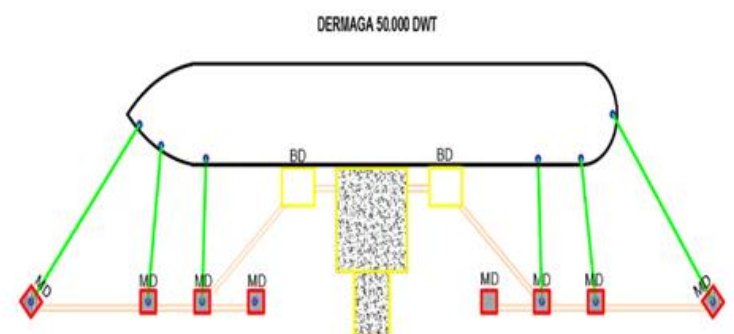

Data Umum Dermaga

- Fungsi dermaga : Jetty

- Lokasi dermaga : :Lamongan Sedayu Lawas, Jawa Timur

- Elevasi lantai dermaga : +4.70 m dari LWS

- Kedalaman rencana :-14.00m dari LWS

\section{Data Situs Tanah:}

Data situs tanah yang digunakan dari hasil penyelidikan tanah $\mathrm{BH} 2$ sebagai berikut:

Tabel 1.

\begin{tabular}{lllll}
\hline $\begin{array}{l}\text { Jenis } \\
\text { tanah }\end{array}$ & $\begin{array}{l}\text { Kedalaman } \\
(\mathrm{m})\end{array}$ & $\begin{array}{l}\text { Interval } \\
\mathrm{d}(\mathrm{m})\end{array}$ & $\begin{array}{l}\text { Nilai } \\
\mathrm{N} \\
\mathrm{SPT}\end{array}$ & $\begin{array}{l}\mathrm{t} /(\mathrm{N}- \\
\mathrm{SPT})\end{array}$ \\
\hline $\begin{array}{l}\text { Lanau } \\
\text { lempung } \\
\text { berpasir }\end{array}$ & 2 & 2 & 1 & 1.000 \\
\hline $\begin{array}{l}\text { Lanau } \\
\text { lempung } \\
\text { berpasir }\end{array}$ & 4 & 2 & 1 & 1.000 \\
\hline $\begin{array}{l}\text { Lanau } \\
\text { lempung } \\
\text { berpasir }\end{array}$ & 6 & & & \\
\hline $\begin{array}{l}\text { Lanau } \\
\text { pasir } \\
\text { berlempu } \\
\text { ng } \\
\text { berkrikil }\end{array}$ & 8 & 2 & 7,5 & 0,200 \\
\hline Lanau & 10 & 2 & 20 & 0,100 \\
\hline
\end{tabular}

pasir

berlempu

ng

berkriki

\begin{tabular}{lllll}
\hline Lanau & 12 & 2 & 25 & 0,08
\end{tabular}

pasir

berlempu

ng

berkrikil

\begin{tabular}{lllll}
\hline Pasir & 14 & 2 & 48 & 0,041
\end{tabular}

berlanau

berkrikil

kompak

\begin{tabular}{lllll}
\hline Pasir & 16 & 2 & 55 & 0,036
\end{tabular}

berlanau

berkrikil

kompak

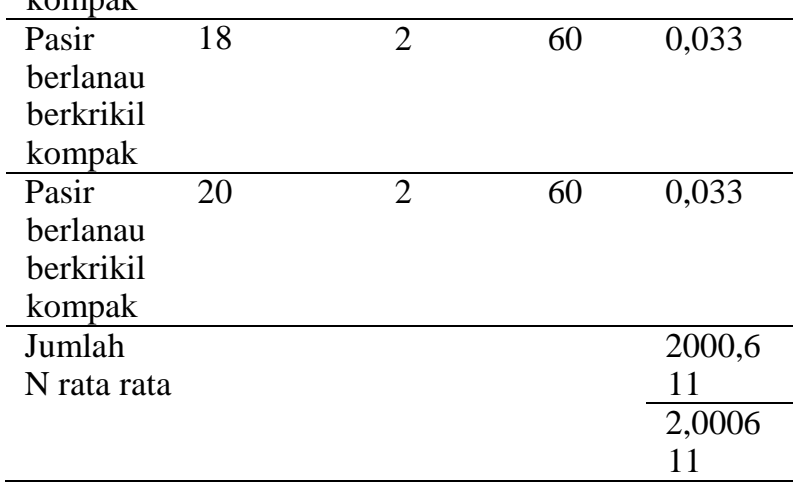

Sumber : Analisis Data

Tabel.2 Spring pile cap (modulus of subgrade reaction)

Jenis tanah

\begin{tabular}{lc} 
& $\left.\mathbf{K N} / \mathbf{m}^{\mathbf{3}}\right)$ \\
\hline Sand & \\
\hline Pasir lepas & $4500-15000$ \\
\hline $\begin{array}{l}\text { Pasir } \\
\text { sedang }\end{array}$ & $9000-75000$ \\
\hline Pasir padat & $60000-120000$ \\
\hline Pasir campur lempung & $30000-75000$ \\
\hline Pasir campur lanau & $22500-45000$ \\
\hline Clay & \\
\hline qu< $4 \mathrm{kPa}$ & $11250-22500$ \\
\hline $4 \mathrm{kPa}<\mathrm{qu}<8 \mathrm{kPa}$ & $22500-45000$ \\
\hline $8 \mathrm{kPa}<\mathrm{qu}$ & $>45000$ \\
\hline
\end{tabular}

Sumber : Analisis Data (2018) 
Tabel 3.

\section{Respon spektrum}

\begin{tabular}{|c|c|}
\hline T(detik) & SA (g) \\
\hline 0 & 0,243 \\
\hline $\mathrm{T}_{\mathrm{O}}$ & 0,607 \\
\hline $\mathrm{T}_{\mathrm{s}}$ & 0,607 \\
\hline $\mathrm{T}_{\mathrm{s}}+\mathrm{O}$ & 0,541 \\
\hline $\mathrm{T}_{\mathrm{S}}+0.1$ & 0,488 \\
\hline $\mathrm{T}_{\mathrm{S}}+0.2$ & 0,445 \\
\hline $\mathrm{T}_{\mathrm{S}}+0.3$ & 0,408 \\
\hline $\mathrm{T}_{\mathrm{S}}+0.4$ & 0,377 \\
\hline $\mathrm{T}_{\mathrm{S}}+0.5$ & 0,351 \\
\hline $\mathrm{T}_{\mathrm{S}}+0.6$ & 0,328 \\
\hline $\mathrm{T}_{\mathrm{S}}+0.7$ & 0,308 \\
\hline $\mathrm{T}_{\mathrm{S}}+0.8$ & 0,29 \\
\hline $\mathrm{T}_{\mathrm{S}}+0.9$ & 274 \\
\hline $\mathrm{T}_{\mathrm{S}}+1$ & 259 \\
\hline $\mathrm{T}_{\mathrm{S}}+1.1$ & 0,247 \\
\hline$T_{S}+1.2$ & 0,235 \\
\hline $\mathrm{T}_{\mathrm{S}}+1.3$ & 0,224 \\
\hline $\mathrm{T}_{\mathrm{S}}+1.4$ & 215 \\
\hline $\mathrm{T}_{\mathrm{S}}+1.5$ & 0,206 \\
\hline$T_{S}+1.6$ & 0,198 \\
\hline $\mathrm{T}_{\mathrm{S}}+1.7$ & 0,19 \\
\hline$T_{S}+1.8$ & 0,183 \\
\hline $\mathrm{T}_{\mathrm{S}}+1.9$ & 0,177 \\
\hline $\mathrm{T}_{\mathrm{S}}+2$ & 0,171 \\
\hline $\mathrm{T}_{\mathrm{S}}+2.1$ & 0,165 \\
\hline $\mathrm{T}_{\mathrm{S}}+2.2$ & 0,16 \\
\hline $\mathrm{T}_{\mathrm{S}}+2.3$ & 0,155 \\
\hline $\mathrm{T}_{\mathrm{S}}+2.4$ & 0,15 \\
\hline $\mathrm{T}_{\mathrm{S}}+2.5$ & 0,146 \\
\hline$T_{S}+2.6$ & 0,142 \\
\hline $\mathrm{T}_{\mathrm{S}}+2.7$ & 0,138 \\
\hline $\mathrm{T}_{\mathrm{S}}+2.8$ & 0,134 \\
\hline $\mathrm{T}_{\mathrm{S}}+2.9$ & 0,13 \\
\hline $\mathrm{T}_{\mathrm{s}}+3$ & 0,127 \\
\hline 4 & 0,125 \\
\hline
\end{tabular}

\begin{tabular}{|l|r|}
\hline Variabel & Nilai \\
\hline PGA (g) & 0,335 \\
\hline$S_{S}(g)$ & 0,694 \\
\hline$S_{1}(g)$ & 0,249 \\
\hline$C_{R S}$ & 0,995 \\
\hline$C_{R 1}$ & 0,947 \\
\hline$F_{P G A}$ & 1 \\
\hline$F_{A}$ & 1 \\
\hline$F_{V}$ & 3 \\
\hline$P S A(g)$ & 0,367 \\
\hline$S_{M S}$ (g) & 0,91 \\
\hline$S_{M 1}$ (g) & 0,748 \\
\hline$S_{D S}$ (g) & 0,607 \\
\hline$S_{D 1}$ (g) & 0,499 \\
\hline$T_{0}$ (detik) & 0,164 \\
\hline$T_{S}$ (detik) & 0,821 \\
\hline
\end{tabular}

Tabel 4.

Kriteria Kapal Tanker

Dead- Loaded Leght Beam Loaded weight Displacement (m) (m) Draft

Tonnage (Tonnes) (m)

\begin{tabular}{lllll}
\hline 1,000 & 1,400 & 60 & 9 & 4,0 \\
\hline 2,000 & 2,800 & 75 & 11 & 5,0 \\
\hline 5,000 & 7,000 & 100 & 14 & 6,0 \\
\hline 10,000 & 13,000 & 140 & 17 & 7,0 \\
\hline 20,000 & 25,000 & 180 & 22 & 9,5 \\
\hline 40,000 & 50,000 & 215 & 29 & 11,0 \\
\hline 60,000 & 75,000 & 245 & 32 & 13,1 \\
\hline 80,000 & 100,000 & 260 & 37 & 13,7 \\
\hline 100,000 & 125,000 & 285 & 41 & 14,6 \\
\hline 120,000 & 150,000 & 295 & 42 & 16,5 \\
\hline 150,000 & 180,000 & 300 & 44 & 17,1 \\
\hline 200,000 & 240,000 & 310 & 47 & 18,9 \\
\hline 250,000 & 300,000 & 325 & 50 & 20,4 \\
\hline 300,000 & 356,000 & 340 & 53 & 22,0 \\
\hline
\end{tabular}

Tabel 5.

\begin{tabular}{|l|l|l|}
\hline tipe fender & E (ton)m & R(ton) \\
\hline $\begin{array}{l}\text { OD } \times \text { ID }= \\
125 \times 65\end{array}$ & 0,13 & 5,20 \\
\hline
\end{tabular}

Tabel 6.

\begin{tabular}{|c|c|c|c|c|c|c|c|}
\hline $\begin{array}{l}\text { Dispace-men } \\
\text { kapal }\end{array}$ & & $\begin{array}{l}\text { gaya } \\
\text { bollard } \\
\text { P }\end{array}$ & $\begin{array}{l}\text { jarak } \\
\text { antar } \\
\text { bollar } \\
\text { d }\end{array}$ & & $\begin{array}{l}\text { gaya } \\
\text { bollard } \\
\text { tegak } \\
\text { lurus } \\
\text { tambatan }\end{array}$ & & $\begin{array}{l}\text { gaya bollard } \\
\text { sepanjang } \\
\text { tambatan }\end{array}$ \\
\hline (ton) & & $(\mathrm{KN})$ & (m) & & $(\mathrm{KN} / \mathrm{m})$ & & $(\mathrm{KN} / \mathrm{m})$ \\
\hline 2.000 & & 100 & 5 & & 15 & & 10 \\
\hline 5.000 & & 200 & 10 & & 15 & & 10 \\
\hline 10.000 & & 300 & 15 & & 20 & & 15 \\
\hline 20.000 & & 500 & 20 & & 25 & & 20 \\
\hline 30.000 & & 600 & 20 & & 30 & & 20 \\
\hline 50.000 & & 800 & $20-25$ & & 35 & & 20 \\
\hline 100.000 & & 1.000 & 25 & & 40 & & 25 \\
\hline 200.000 & & 1.500 & 30 & & 50 & & 30 \\
\hline $\begin{array}{l}\text { Diameter } \\
(\mathrm{cm})\end{array}$ & $\begin{array}{l}1 \\
5\end{array}$ & $20 \quad 25$ & 30 & 35 & 40 & 45 & 50 \\
\hline $\begin{array}{l}\text { Gaya } \\
\text { tarik ijin } \\
\text { (ton) }\end{array}$ & 5 & $10 \quad 20$ & 35 & 50 & 70 & $\begin{array}{l}10 \\
0\end{array}$ & $\begin{array}{ll}12 & 15 \\
0 & 0\end{array}$ \\
\hline
\end{tabular}


ANALISIS DAN HASIL PEMBAHASAN

Kualitas material

1. Mutu Beton

Untuk elemen struktur pile cap, balok, dan pelat dermaga menggunkan mutu beton $\mathrm{K}-550$

2. Baja untuk tulangan

Untuk tulangan beton yang digunakan yaitu mutu U-24 (polos) fy $=2400 \mathrm{~kg} / \mathrm{cm}^{2}$ dan mutu U-39 (ulir) fy $=3900 \mathrm{~kg} / \mathrm{cm}^{2}$

Elevasi dermaga

Untuk HWS yang direncanakan dengan tinggi 2,20 $\mathrm{m}$ dari LWS 0,00. Diambil dari pengamatan dilapang didapat $2,02 \mathrm{~m}$.

Gaya vertikal

Gaya Vertikal terdiri dari berat sediri struktur dermaga dengan $\gamma$ beton $=2,4$ ton $/ \mathrm{m}^{3}$ ybaja $=7,85$ ton $/ \mathrm{m} 3$ untuk bedan mati untuk beban hidup merata terdiri dari beban manusia dan air hujan 250 $\mathrm{kg}$

\section{Gaya Horizontal}

\section{Fender}

\section{Perencanaan fender}

Type kapal 50.000 DWT (kapal tanker)

Gross tonage $40.000 \quad=50000$ ton

Full displacement $(\mathrm{W}) \quad=40000$ ton

Length/ Panjang $($ Loa $) \quad=215 \mathrm{~m}$

Width/Lebar $(\mathrm{B}) \quad=29 \mathrm{~m}$

Full draft $(\mathrm{d}) \quad=11 \mathrm{~m}$

Sudut merapat $\quad=10 \%$

Energi benturan kapal ke dermaga dihitung dengan

rumus

$E=\frac{W V^{2}}{2 G_{W}} C_{m} C_{e}$ Menghitung $C_{m}$

$C_{b}=\frac{W}{L_{p p} B d \gamma_{0}}$

$C_{b} \quad=\frac{40000}{239,08 \times 29 \times 11 \times 1,025}$

$$
=0,51077
$$

$C_{m}=1+\frac{\pi}{2 C_{b}} \frac{d}{B}$

$C_{m}=1+\frac{3,14}{2 \times 0,511} \times 29$

$=2,165920453$

Menghitung $C_{e}$

Dengan menggunakan nilai $\mathrm{Cb}=0,51($ diambil 0,5$)$ didapat

$$
\frac{\mathrm{r}}{\mathrm{loa}}=0,205
$$

Untuk kapal yang bersandar di dermaga

$$
1=1 / 4 \text { loa }
$$

$1=1 / 4 \times 215=53,75 \mathrm{~m}$

Sehingga didapat

$$
\begin{aligned}
& r=0,205 \times 53,75 \\
& \mathrm{Ce}=\frac{1}{1+(1 / \mathrm{r})^{2}}
\end{aligned}
$$

$\mathrm{Ce}=$

$$
\frac{1}{1+(53,75 / 11,02)^{2}}
$$

Energi benturan :

$$
E=\frac{4000 \times 0,0007 \times 2,16 \times 0,04=0,12}{2 \times 9,81}
$$

Energi yang membentur dermaga adalah setengah dari energi benturan yang diakibatkan oleh kapal (1/2 E).Akibat benturan tersebut ,dermaga memberikan gaya reaksi F $1 / 2$ d. Dengan menyakan nilai tersebut.

$$
\begin{array}{ll}
\mathrm{E} & =0,120387049 \mathrm{Ton} / \mathrm{m} \\
\mathrm{F} 1 / 2 \mathrm{~d}=1 / 2 \mathrm{E} & \\
\mathrm{Fd}=\mathrm{E} & \\
\mathrm{E} \quad=0,060193525 \mathrm{Ton} / \mathrm{m}
\end{array}
$$

Jarak maksimum antar fender (L) dihitung dengan rumus

$$
L=2 \sqrt{r^{2}-(r-h)^{2}}
$$

Untuk kapal tanker 50000 DWT

$$
\begin{aligned}
& \log \mathrm{r}=-0,113+0,440 \log (\mathrm{DWT}) \\
& \log \mathrm{r}=-0,133+0,44 \log 50000 \\
& \begin{aligned}
& =1,9345 \\
& =11,02 \mathrm{~m}
\end{aligned} \\
& \mathrm{~h}=\text { tinggi fender }=200 \quad \mathrm{~cm}= \\
& 2 \\
& \mathrm{~L}=2 \sqrt{ } 11,02^{2}-(11,02-2)^{2}=
\end{aligned}
$$




\section{Bollard}

Perencanaan bollard diambil berdasarkan gaya terbesar diantara gaya tarik boulder sendiri, gaya angin dan gaya arus.

Akibat beban angin

$$
\begin{aligned}
\mathrm{Rw} & =1,1 \times \mathrm{Qa} \times \mathrm{Aw} \\
& =0,062 \times \mathrm{v}^{2} \\
& =0,061 \times 12,96^{2} \\
& =10,41 \mathrm{~kg} / \mathrm{m}^{2}
\end{aligned}
$$

Tinggi kapal yang terkena angin = light draft

light draft $\quad=\underline{\mathrm{W}}-$ ( berat kapal (DWT) $\mathrm{x}$ full draft $=40000-50000 \times 11$

$$
\text { berat kapal }
$$

(DWT)

$$
50000
$$

$$
=-2,2 \quad \mathrm{~m}
$$

Maka tinggi kapal yang terkena angin adalah luas kapal yang terkena $\operatorname{angin}\left(A_{W}\right)=$ Loa $\mathrm{x}$ tinggi yang terken a angin

$$
\begin{aligned}
& =215 \times 2,2 \\
& =473 \mathrm{~m}^{2}
\end{aligned}
$$

$R_{w} \quad=1,1 \times Q_{a} \times A_{w}$

$=1,1 \times 10,4136192 \times 473$

$=5418,20607 \mathrm{~kg}=5,41820607$ ton

Akibat beban arus $(\mathrm{F})$

luas kapal yang terkena arus $(A c)=\mathrm{d} \times$ Loa

\begin{tabular}{|c|c|c|c|c|c|c|c|c|c|}
\hline $\begin{array}{l}\text { teb } \\
\text { al } \\
(\mathrm{m} \\
\mathrm{m})\end{array}$ & $\begin{array}{l}\text { deck } \\
\text { ing } \\
(\mathrm{mm} \\
)\end{array}$ & $\begin{array}{l}\text { qu } \\
(\mathrm{kg} / \mathrm{m} \\
2)\end{array}$ & $\begin{array}{l}\text { ly } \\
\text { (m }\end{array}$ & $\begin{array}{l}\mathrm{lx} \\
\text { (mm } \\
\text { ) }\end{array}$ & $\begin{array}{l}\underline{1} \\
y \\
x\end{array}$ & $\begin{array}{l}\text { ko } \\
\text { ef } \\
x\end{array}$ & $\begin{array}{l}\text { lok } \\
\text { asi }\end{array}$ & $\begin{array}{l}\mathrm{Mu} \\
(\mathrm{kg}- \\
\mathrm{m})\end{array}$ & Tpasang \\
\hline & & & 11 & & & 25 & & & \\
\hline 15 & & 23748 & 00 & 1100 & & & M & 176 & \\
\hline 00 & 50 & 5 & 0 & 0 & 1 & & ulx & 400 & Ø13-150 \\
\hline & & & 11 & 1100 & & 25 & & & Ø13-150 \\
\hline 15 & & 23748 & 00 & 0 & & & M & 176 & \\
\hline 00 & 50 & 5 & 0 & & 1 & & uly & 400 & \\
\hline & & & 11 & 1100 & & 51 & & & $\varnothing 13-150$ \\
\hline 15 & & 23748 & 00 & 0 & & & M & 176 & \\
\hline 00 & 50 & 5 & 0 & & 1 & & utx & 400 & \\
\hline & & & 11 & 1100 & & 51 & & & Ø13-150 \\
\hline 15 & & 23748 & 00 & 0 & & & M & 176 & \\
\hline 00 & 50 & 5 & 0 & & 1 & & uty & 400 & \\
\hline
\end{tabular}

$$
=11 \times 215
$$$$
=2365 \mathrm{~m}^{2}
$$

\begin{tabular}{|c|c|c|c|c|c|c|c|c|c|}
\hline $\begin{array}{c}\text { Posi } \\
\text { si }\end{array}$ & $\begin{array}{c}\text { Mom } \\
\text { en } \\
\text { Ultim } \\
\text { ate } \\
\text { terjad } \\
\text { i } \\
\text { (kgm) }\end{array}$ & $\begin{array}{l}\mathrm{b} \\
(\mathrm{m} \\
\mathrm{m})\end{array}$ & $\begin{array}{l}\mathrm{h} \\
(\mathrm{m} \\
\mathrm{m})\end{array}$ & $\begin{array}{l}\text { Diamet } \\
\text { er } \\
\text { tulanga } \\
\mathrm{n}(\mathrm{mm})\end{array}$ & $\begin{array}{l}\text { Rho } \\
\text { Pakai }\end{array}$ & $\begin{array}{c}\text { Tul } \\
\text { Tari } \\
\mathrm{k} \\
\text { Pas } \\
\text { ang } \\
\text { (As } \\
\text { ) } \\
\text { (bh) }\end{array}$ & $\begin{array}{c}\text { As } \\
\text { Pasan } \\
\mathrm{g} \\
(\mathrm{mm} 2 \\
)\end{array}$ & $\begin{array}{c}\text { Tul } \\
\text { Teka } \\
\text { n } \\
\text { Pasan } \\
\text { g } \\
\text { (As') } \\
\text { (bh) }\end{array}$ & $\begin{array}{c}\mathrm{As}^{\prime} \\
\text { pasan } \\
\mathrm{g} \\
(\mathrm{mm} 2 \\
)^{2}\end{array}$ \\
\hline $\begin{array}{c}\text { tum } \\
\text { pua } \\
\mathrm{n}\end{array}$ & \multirow{2}{*}{$\begin{array}{c}2003 \\
16\end{array}$} & 400 & 800 & 19 & $\begin{array}{c}0,003 \\
5\end{array}$ & 20 & $\begin{array}{l}5667, \\
7\end{array}$ & 10 & $\begin{array}{c}2833, \\
9\end{array}$ \\
\hline $\begin{array}{c}\text { lapa } \\
\text { nga } \\
\text { n }\end{array}$ & & 400 & 800 & 19 & $\begin{array}{c}0,003 \\
5\end{array}$ & 10 & $\begin{array}{l}2833, \\
9\end{array}$ & 20 & $\begin{array}{c}5667 \\
7\end{array}$ \\
\hline $\begin{array}{c}\text { tum } \\
\text { pua } \\
\text { n }\end{array}$ & \multirow{2}{*}{$\begin{array}{c}1855 \\
67\end{array}$} & 400 & 700 & 19 & $\begin{array}{c}0,003 \\
5\end{array}$ & 20 & $\begin{array}{l}5667, \\
7\end{array}$ & 10 & $\begin{array}{l}2833, \\
9\end{array}$ \\
\hline $\begin{array}{c}\text { lapa } \\
\text { nga } \\
\text { n }\end{array}$ & & 400 & 700 & 19 & $\begin{array}{c}0,003 \\
5\end{array}$ & 10 & $\begin{array}{l}2833, \\
9\end{array}$ & 20 & $\begin{array}{l}5667, \\
7\end{array}$ \\
\hline $\begin{array}{c}\text { tum } \\
\text { pua } \\
\text { n }\end{array}$ & \multirow{2}{*}{$\begin{array}{c}1803 \\
85\end{array}$} & 400 & 600 & 19 & $\begin{array}{c}0,003 \\
5\end{array}$ & 10 & $\begin{array}{l}2833, \\
85\end{array}$ & 5 & $\begin{array}{c}1416, \\
9\end{array}$ \\
\hline $\begin{array}{c}\text { lapa } \\
\text { nga } \\
\text { n }\end{array}$ & & 400 & 600 & 19 & $\begin{array}{c}0,003 \\
5\end{array}$ & 5 & $\begin{array}{l}1416, \\
92\end{array}$ & 10 & $\begin{array}{c}2833, \\
8\end{array}$ \\
\hline
\end{tabular}

$$
R_{A} \quad=\operatorname{Cc} \times \gamma w \times A_{c} \times\left(\frac{V_{c}^{2}}{2 g}\right)
$$

\begin{tabular}{|c|c|c|c|c|c|c|c|}
\hline \multirow{2}{*}{ No } & \multirow{2}{*}{$\begin{array}{l}\text { Type } \\
\text { balok }\end{array}$} & \multirow{2}{*}{ Posisi } & \multirow{2}{*}{$\mathrm{Vu}(\mathrm{N})$} & \multicolumn{3}{|c|}{ Dimensi (mm) } & \multirow{2}{*}{$\begin{array}{c}\begin{array}{c}\mathrm{S} \\
\text { pasang }\end{array} \\
(\mathrm{mm})\end{array}$} \\
\hline & & & & b & $\mathrm{h}$ & $\begin{array}{c}\varnothing \\
\text { sengkang }\end{array}$ & \\
\hline \multirow{2}{*}{1} & \multirow{2}{*}{$\begin{array}{c}\text { B1 } \\
40 / 80\end{array}$} & tumpuan & \multirow{2}{*}{88969,95} & 400 & 800 & 13 & 80 \\
\hline & & lapangan & & 400 & 800 & 13 & 80 \\
\hline \multirow{2}{*}{2} & \multirow{2}{*}{$\begin{array}{c}\text { B2 } \\
40 / 70\end{array}$} & tumpuan & \multirow{2}{*}{28867} & 400 & 800 & 13 & 100 \\
\hline & & lapangan & & 400 & 800 & 13 & 100 \\
\hline \multirow{2}{*}{3} & \multirow{2}{*}{$\begin{array}{c}\text { B3 } \\
40 / 60\end{array}$} & tumpuan & \multirow{2}{*}{61962} & 400 & 600 & 13 & 100 \\
\hline & & lapangan & & 400 & 600 & 13 & 100 \\
\hline
\end{tabular}$$
=1 \times 1025 \times 2365 \times\left(\frac{0,11^{2}}{2 \times 9,81}\right)
$$$$
=1495,000637 \mathrm{~kg}=1,495000637 \text { ton }
$$

Bollard yang digunakan adalah 150 ton

\section{Plat}

Hasil perhitungan plat pada SAP2000v14

\begin{tabular}{|c|c|c|}
\hline $\begin{array}{l}\text { Kedalaman } \\
\text { (m) }\end{array}$ & Jenis tanah & $\mathrm{N}$ \\
\hline 2 & $\begin{array}{c}\text { Lanau lempung } \\
\text { berpasir }\end{array}$ & 1 \\
\hline 4 & $\begin{array}{c}\text { Lanau lempung } \\
\text { berpasir }\end{array}$ & 1 \\
\hline 6 & $\begin{array}{c}\text { Lanau lempung } \\
\text { berpasir }\end{array}$ & 7,5 \\
\hline 8 & $\begin{array}{c}\text { Lanau lempung } \\
\text { berpasir }\end{array}$ & 20 \\
\hline 10 & $\begin{array}{c}\text { Lanau pasir } \\
\text { berlempung } \\
\text { krikil }\end{array}$ & 22,5 \\
\hline 12 & $\begin{array}{c}\text { Lanau pasir } \\
\text { berlempung } \\
\text { krikil }\end{array}$ & 25 \\
\hline 14 & Lanau lempung & 48 \\
\hline
\end{tabular}

\section{Balok}

Hasil perhitungan momen balok pada SAP2000v14

Hasil perhitungan Geser pada SAP2000v14

5. Perencanaan pondasi tiang

Daya dukung satu tiang berdaserkan data SPT

$\mathrm{Qu}=\mathrm{Qp}+\mathrm{Qsi} / 3$

Tabel 4.8 data titik bor BH 2 


\begin{tabular}{ccc}
\hline \hline \multicolumn{3}{c}{ berpasir } \\
\hline 16 & $\begin{array}{c}\text { Lanau lempung } \\
\text { berpasir }\end{array}$ & 55 \\
\hline 18 & $\begin{array}{c}\text { Lanau lempung } \\
\text { berpasir }\end{array}$ & 60 \\
\hline 20 & $\begin{array}{c}\text { Lanau lempung } \\
\text { berpasir }\end{array}$ & 60 \\
\hline
\end{tabular}

$$
=9 \sim 9 \text { Tiang }
$$

Check kapasitas group pile

$\mathrm{Qu} \quad=(40 \times \mathrm{Nb} \times \mathrm{Ap}) \longrightarrow \mathrm{Nb}=(\mathrm{N} 1+$ N2)/2

Untuk mencari $\mathrm{Nb}$ diperlukan $8 \mathrm{D}$ dan $3 \mathrm{D}$ pile .

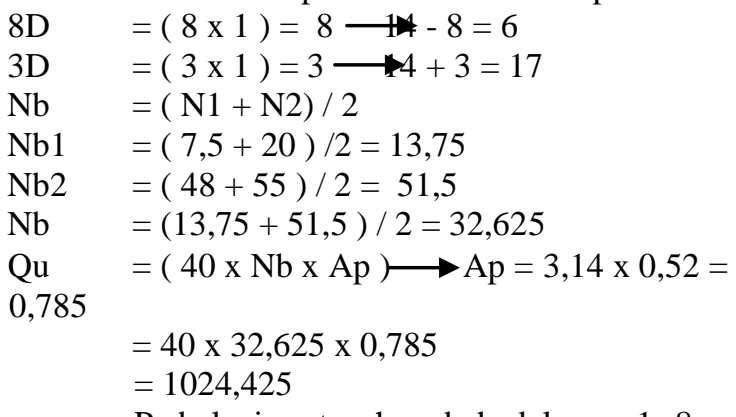

Pada lapisan tanah pada kedalaman 1- $8 \mathrm{~m}$ adalah jenis tanah lanau lempung berpasir, Pada lapisan tanah pada kedalaman 8 -12 m adalah jenis tanah lanau pasir berlempung krikil, dan Pada lapisan tanah pada kedalaman 12-20 m adalah jenis tanah lanau lempung berpasir

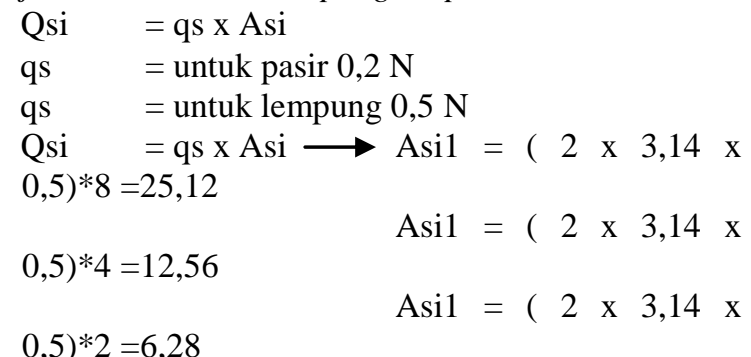

$0,5) * 2=6,28$

Nilai (Qsi) didapat

$$
\begin{aligned}
\text { Qsi1 } & =0,5 \times 32,625 \times 25,12 \\
& =409,77 \\
\text { Qsi2 } & =0,2 \times 32,625 \times 12,56 \\
& =40,977 \\
\text { Qsi3 } & =0,5 \times 32,625 \times 6,28 \\
& =102,4425 \\
\text { Qsi } & =409,77+40,99+102,44 \\
& =553,2
\end{aligned}
$$

Daya dukung satu tiang pancang berdasarkan spt

$$
\begin{aligned}
\mathrm{Pu} & =(\mathrm{Qu}+\mathrm{Qsi}) / 3 \\
& =\underline{1024,425+553,2} \\
& =525,875
\end{aligned}
$$

Digunakan pile produk PP dengan D100mm yang mampu menerima axial 674,56 ton Maka jumlah tiang

$$
\begin{aligned}
\mathrm{n} & =\frac{\mathrm{Nu}}{\mathrm{Pu}} \\
& =\frac{487}{52,5}
\end{aligned}
$$

$$
P \max =\underline{\mathrm{Pu}}+\underline{\mathrm{My} \times \mathrm{Xmax}}+\underline{\mathrm{Mx}}
$$

$$
\mathrm{Y}^{2} \text { Total } \mathrm{np} \quad \mathrm{n} \times \mathrm{X}^{2} \text { Total } \quad \mathrm{n} \text {. }
$$

Jarak pile ke titi pusat $\operatorname{arah} \mathrm{x}$

$$
\begin{array}{rlr}
\mathrm{x} 1=3 \mathrm{~m} & \mathrm{x} 12=9 \mathrm{~m}^{2} \\
\mathrm{x} 2 & \mathrm{x} 22=16 \mathrm{~m}^{2} \\
\mathrm{x} 3=3 \mathrm{~m} & \mathrm{x} 32=9 \mathrm{~m}^{2} \\
\mathrm{x} 4=0 \mathrm{~m} & \mathrm{x} 42=0 \mathrm{~m}^{2} \\
& \mathrm{X}^{2} \text { Total } & =34,00 \mathrm{~m}^{2}
\end{array}
$$

$\operatorname{arah} \mathrm{y}$

$$
\begin{aligned}
& \mathrm{y} 1=3 \mathrm{~m} \quad \mathrm{y} 12=9 \mathrm{~m}^{2} \\
& \mathrm{y} 2=4 \mathrm{~m} \quad \mathrm{y} 22=16 \mathrm{~m}^{2} \\
& \mathrm{y} 3=3 \mathrm{~m} \quad \mathrm{y} 32=9 \mathrm{~m}^{2} \\
& \mathrm{y} 4=0 \mathrm{~m} \quad \mathrm{y} 42=0 \mathrm{~m}^{2} \\
& \mathrm{Y}^{2} \text { Total }=34,00 \mathrm{~m}^{2} \\
& P \max =\underline{47850}+\underline{24 \times 3}+\underline{32 \times 3} \\
& 99 \times 349 \times 34 \\
& =5316,6+23,5+31,37 \\
& =5371,5 \mathrm{Kg}
\end{aligned}
$$

Pmax $<\mathrm{Pa}$

$5371,5<25434$

$\mathrm{OK}$

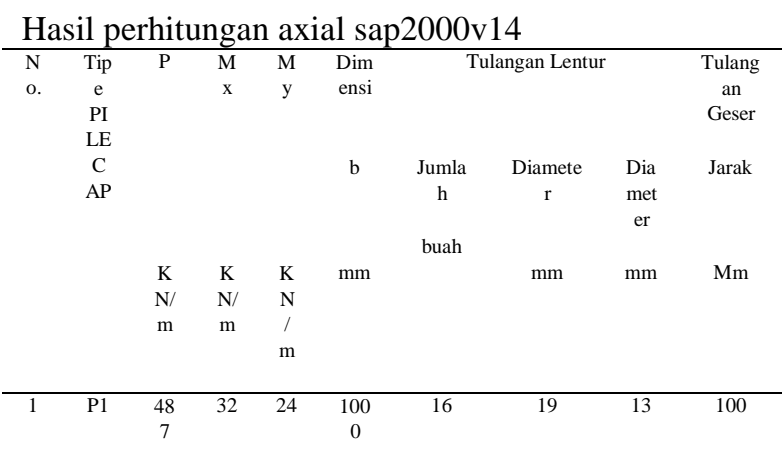




\section{PCACOL}

Output perhitungan kapsitas pile cap $100 \mathrm{~cm}$ dengan PCACOL (un-axial x)

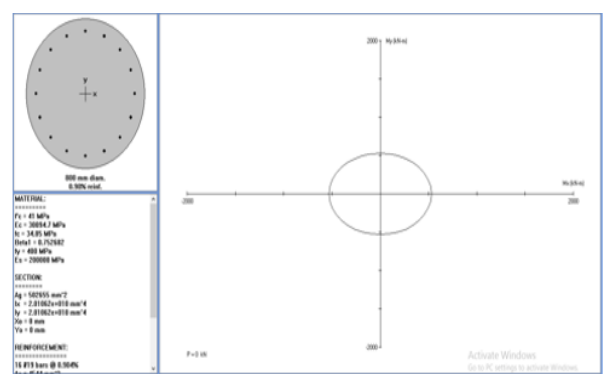

Output perhitungan kapsitas pile cap $100 \mathrm{~cm}$ dengan PCACOL (biaxial)

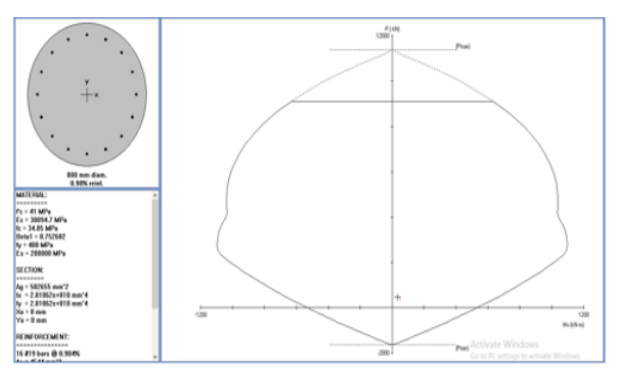

\section{KESIMPULAN DAN SARAN}

\section{Kesimpulan}

Berdasarkan hasil pengelolahan data yang telah dilakukan tentang perencanaan dolphin dermaga PT. NATPAC GRAHA ARTHAMAS dapat ditarik kesimpulan sebagai berikut.

1.Elevasi puncak yang dipakai untuk perencanaan struktur Breasting dolphin dan mooring dolphin adaalah HWS +2,20m dari LWS 0,00.

2.Dari hasil perhitungan energi benturan kapal , dipilih fender ukuran OD x ID 1200 x 700 mm, dari benturan kapal yang bekerja pada dermaga sebesar $887 \mathrm{~kg} / \mathrm{m}$.

3.Akibat energi kinetik pada struktur dermaga terjadi gaya axial maksimal pada tiang pancang Pult 530ton dan momen maksimal Mult 24ton.m yang diperoleh dari hasil output pemodelan sap2000. tiang pancang direncanakan menggunakan tiang pancang beton precast produk PP dengan D1m yang mempunyai Pijin 674,56 ton dan Mijin 261,20 ton.m .karena Pult 530 ton < 674,56 ton dan Mult 24ton.m < Mijin 261,20 ton.m maka tiang pancang bisa dipakai pada perencanaan.

\section{Saran}

Berdasarkan hasil kesimpulan di atas, saran untuk perencanaan dolphin dermaga PT. NATPAC GRAHA ARTHAMAS adalah sebagai berikut.

1.Perencanaan selanjutnya perlu menghitung RAB.

\section{DARTAR PUSTAKA}

Standar Nasional Indonesia.2012.SNI-03-1726-

2012-Standar

Perencanaan Ketahanan Gempa Untuk Struktur Bangunan Gedung.

Bambang Triatmodjo. 2010. Perencanaan

Pelabuhan.

Yogyakarta:Beta Offset

Bambang Triatmodjo.2010. Teknik Pantai.

Yogyakarta:Beta Offset

M.J.Thomlinson 1977. Pile Design and

Construction practice

Desain Spektra indonesia

http://puskim.pu.go.id/Aplikasi/desain_sp

ektra_indonesia_2011/

$\underline{\text { dibuka pada } 20 \text { agustus } 2018}$ 